Veer, A.J.E. de, Kerkstra, A.

Feeling at home in nursing homes.

Journal of Advanced Nursing: 35, 2001, nr. 3, p. 427-434

\begin{tabular}{|c|c|}
\hline Postprint Version & 1.0 \\
\hline Journal website & http://www.blackwell-synergy.com \\
\hline Pubmed link & $\begin{array}{l}\text { http://www.ncbi.nlm.nih.gov/entrez/query.fcgi? } \mathrm{cmd}=\text { Retrieve\&db=pubmed\&dop } \\
\mathrm{t}=\text { Abstract\&list_uids=11489028\&query hl=31\&itool=pubmed_docsum }\end{array}$ \\
\hline
\end{tabular}

Correspondence: Anke de Veer, Netherlands Institute of Primary Health Care (NIVEL), PO Box 1568, 3500 BN Utrecht, The Netherlands. E-mail: a.deveer@nivel.nl

ISSUES AND INNOVATIONS IN NURSING PRACTICE

\title{
Feeling at home in nursing homes
}

\begin{abstract}
ANKE J.E. DE VEER PHD - Research Fellow, Department of Nursing and Caring Research, Netherlands Institute of Primary Health Care, Utrecht, The Netherlands
\end{abstract}

ADA KERKSTRA PHD - Department Manager, Department of Nursing and Caring Research, Netherlands Institute of Primary Health Care, Utrecht, The Netherlands

Aim. The purpose of this study was to examine determinants of feeling at home and in particular the privacy in nursing homes in The Netherlands. The first question was to what extent nursing homes differed in the degree residents feel at home and experience privacy. The second question was whether feeling at home is related to privacy in the nursing homes.

Background. Feeling at home is of particular importance to residents of nursing homes because the average length of stay in The Netherlands is about 16 months. A growing number of people are of the opinion that the privacy of the residents has to be improved. Privacy in nursing homes, therefore, has been high on the political agenda over the last few years. Four aspects of privacy were distinguished: privacy related to the characteristics of the building, privacy as a consequence of the attitude of nurses towards residents, privacy in terms of choice and control over time schedules and activities, and privacy related to the amount of disturbance caused by other residents.

Design. The data were collected from individual interviews with 686 residents and family-members in 36 nursing homes in The Netherlands.

Results. Following quantitative data analysis, it was found that nursing homes differed in the proportion of residents feeling at home as well as in three aspects of privacy. Differences in feeling at home were found to be related to privacy, especially to the perceived attitudes of nurses and perceived disturbance caused by other residents. A weak relationship was found between residents and their perceived privacy of the building.

Conclusions. A significant amount of variation in privacy was found at the nursing home level. This implies that feeling at home is not only individually determined but can be influenced by the nursing home's management policy.

\section{INTRODUCTION}

Some individuals have great difficulty establishing a sense of home in alternative settings (Hammer 1999). Losing one's home can be a devastating event that threatens one's quality of life (Bauman 1993). Knowledge of interventions that contribute to establishing a sense of home is therefore 
valuable. The objective of this article is to examine how characteristics of the nursing home, and in particular privacy, relate to the experience of feeling at home.

Feeling at home is of particular importance to residents of nursing homes because of the permanence of their situation. In the Netherlands, the average length of stay is 15.8 months (Spaan \& Bartels 1999). Nursing homes in The Netherlands provide care for predominantly older people with chronic diseases and physical and/or mental disorders and disabilities. Basically, two groups of residents can be distinguished: people with physical illness and people with mental illness. In The Netherlands, these groups are cared for in separate wards or in separate institutions (Ribbe 1993). A growing number of people thought that the quality of care in nursing homes had to be improved. Also, attitudes towards older people have changed to seeing them more as consumers rather than patients (Meijer et al. 2000).

As a result of these developments, privacy in nursing homes has been high on the political agenda in The Netherlands over the last few years. When searching for policy measures to improve residents' privacy, the Dutch Ministry of Health defined privacy as the opportunity to live one's own life and respect for one's personal lifestyle (VWS 1996a). In this study, we distinguished four aspects of privacy. First, privacy was expected to be enhanced by improving the building (VWS 1996a). Residents sharing rooms with others and insufficient provision of private space were considered undesirable. Measures were taken to replace rooms for three or more by rooms for one or two (VWS 1996b). Other structural changes that contribute to increased privacy are living rooms for smaller groups of residents and the creation of quiet places. The degree of personalization of residents' rooms was also found to relate to their satisfaction with the nursing home (Kruzich et al. 1992).

Secondly, it was stressed that feelings of privacy were related to resident-centredness, particularly the attitude of nurses (VWS 1996a). Resident-centredness implies respect for residents, listening to their needs, showing genuine interest in and openness towards them.

A third aspect of privacy is the opportunity to live one's own life and refers to respect for autonomy (Van Thiel \& Van Delden 1997). The Dutch Association for Nursing Home Care (every Dutch nursing home is a member of this association) formulated respect for autonomy as a criterion for high quality care. Autonomy was used as meaning 'independence' (Van Thiel \& Van Delden 1997). Autonomy refers to the choice of and control over matters such as bedtime, getting-up time, care routines, use of telephone, and trips outside the nursing home (Jirovec \& Maxwell 1993, Kane et al. 1997). Studies have shown a positive relationship between perceived control (the feeling of being in charge of one's own life) and the psychological well-being of residents (Brubaker 1996).

A fourth factor often mentioned by nurses and other professionals within the field of nursing homes is the attitude of residents towards each other, and in particular the extent to which a resident experiences disturbance caused by others (VWS 1996a).

Very little is known about how residents of nursing homes assess privacy. Most studies focus on the opinions of staff or family members. Because research findings suggest that perceptions of residents differ from those of family or professionals (Lavizzo-Mourey et al. 1992, Bliesmer \& Earle 1993, Pearson et al. 1993), we aimed to interview the residents themselves. Studies of differences among nursing homes are also scarce. The study discussed here was designed to gain insight into the influence of the aforementioned privacy-related aspects in nursing homes on residents' experiences of feeling at home. Sources of information are the residents themselves.

The first question to be answered refers to differences between nursing homes: To what extent do nursing homes differ in the degree to which residents feel at home and in the privacy experienced?

The second question refers to the determinants of feeling at home: Are differences in feeling at home on the part of residents related to contextual differences in privacy, that is, the perceived quality of the environment/building, the flexibility of routines, resident-centredness and disturbance caused by other residents? These aspects are shown in the first box of Figure 1. In the analyses other possible determinants of feeling at home were taken in account. These determinants are (see Figure 1):

- Preferences of residents with respect to characteristics of the building, flexibility of routines, resident-centredness and disturbance. The influence of privacy cannot be studied without knowing what is important to the resident (Linder-Pelz 1982). Several studies have shown that fulfilment of expectations is an important predictor of satisfaction (Swan et al. 1985, Like \& Zyzanski 1987). Differences in feeling at home might also be related to differences in expectations. 
-Individual (background) characteristics of the residents (gender, age, time in nursing home, activities of daily living [ADL], type of problem, number of persons sharing the room). Older residents and women tend to report higher levels of satisfaction (Mattiassion \& Andersson 1997). We also hypothesized that the duration of the care influences feeling at home. Admission to a nursing home is a life-event that can seriously affect one's well-being. For many people, it is an irreversible situation in which one loses autonomy, personal belongings and life with one's spouse. One has to face the impossibility of living at one's own home again. Adjustment to this new situation needs time and therefore we hypothesized that the duration of the care relates positively to the chance of feeling at home in the new environment.

-(Background) characteristics of the setting of the nursing home (type of home, urbanization of municipality, number of beds in the nursing home).

\section{[ FIGURE 1 ]}

\section{THE STUDY}

\section{Methods}

Sample

Eighty nursing homes, a sample randomly chosen from all 326 nursing homes in The Netherlands in 1996, were asked to participate. A total of 36 nursing homes agreed to participate (response $45 \%$ ). In each nursing home a randomly selected sample of residents was interviewed. If a resident could not be interviewed (which was the case in $95 \%$ of the residents with mental illness and $20 \%$ of the residents with physical illness) a significant other was asked. This person, often a resident's offspring, was asked to reflect the opinion of the resident.

The opinions of a total of 686 residents were gathered (response 73\%). Residents with physical illness were overrepresented in the sample (Table 1). The characteristics of the sample with respect to age, gender, and length of stay were similar to those of the total population of residents in nursing homes in The Netherlands (Table 1). Assessment of the activities of daily living (Barthel-index, Post (1997), 10 items, the reliability of this scale in terms of internal consistency Cronbach's $\alpha=0 \cdot 88$ ) showed that, according to the criteria of Wade and Hewer (1987), 39\% of the residents were very severely disabled, $30 \%$ severely disabled, $17 \%$ moderately disabled and $14 \%$ slightly disabled.

\section{[ TABLE 1 ]}

\section{Interview}

The interview questions were formulated by the authors. They were based on literature and current ideas about aspects of privacy of the Ministry of Health (VWS 1996a, b), the Dutch Association for Nursing Home Care, and organized interest groups of nursing home residents (De Veer \&Kerkstra 1998). In general, the questions and alternative responses in the interview were simple because it was vital that as many residents as possible understood and were able respond to the questions. The alternative responses were 'yes' or 'no'.

Feeling at home was measured by asking: Do you feel at home in this nursing home?

Perceived privacy was measured with a 33 statement selfconstructed questionnaire (De Veer et al. 1998). These statements covered four aspects. Characteristics of the building were measured by six questions (Cronbach's $\alpha=0 \cdot 61$ ). Four of these referred to opportunities to make a private phone call, to be alone, to talk to others in private, and to receive visitors. Two questions related to using one's own furniture and hanging pictures on the walls. The number of characteristics present was counted (minimum score $=0$, maximum score $=6$ ).

Flexibility of routines was measured in 13 questions (Cronbach's $\alpha=0 \cdot 75$ ). Ten of these referred to activities and the question was whether the resident decided when to wash, shower, eat, receive visitors, go to bed, go to the toilet, etc. Three questions referred to choice of food and beverages. 
The final score was the sum of activities the resident was free to choose (minimum $=0$, maximum=13).

Resident-centredness was measured by 13 questions (Cronbach's $\alpha=0 \cdot 72$ ). Eight of these related to being treated with respect and kindness, the presence of someone to confide in, and interest in the resident's life and life-history. The other five items assessed the resident's participation in care. The total number of items referring to a resident-centred attitude was counted (minimum $=0$, maximum=13).

Finally, disturbance caused by other residents was measured by one item: do you experience disturbance caused by the behaviour or problems of other residents? Privacy preferences were measured in 33 questions about the importance of the characteristics of the building (Cronbach's $\alpha=0 \cdot 83$ ), flexibility of routines (Cronbach's $\alpha=0 \cdot 88$ ), resident-centredness (Cronbach's $\alpha=0 \cdot 87$ ) and disturbance caused by other residents in having a feeling of psychological well-being in the nursing home.

\section{Data analysis}

Firstly, we explored the differences between nursing homes in respect of the percentage of residents feeling at home and their perceived privacy. For the variables at a dichotomous level (feeling at home and disturbance caused by other residents), chi-square analyses were used. For the variables at an interval level (building, flexibility of routines, resident-centredness), intraclass correlation coefficients were calculated. These coefficients reflect the proportion of total variance of a variable that is associated with the class (in this case the nursing home) to which it belongs.

The second step in the analysis was to explore whether feeling at home was related to privacy, privacy preferences, background characteristics of the resident and characteristics of the nursing home. After exploring bivariate relations between these variables and the dependent variable, a logistic regression analysis was carried out. A multilevel analysis (MLA) was carried out to control for the reliability of the conclusions of the logistic regression analysis. With residents being nested within nursing homes, the data were organized into two levels: the nursing home level and the resident level. The MLA makes use of the hierarchical structure of the data and offers more precise estimates of the regression coefficients and their standard errors and subsequently reduces the risk of making wrong conclusions (Hox 1995). The independent variables represented two levels: the nursing home level and the resident level. Predictor variables at the nursing home level included the setting of the nursing home (target group is residents with physical illness, residents with mental illness or both; degree of urbanization of the nursing home location; number of beds). The other predictors were at the resident level. If MLA shows the same results as the logistic regression analysis there is evidence that the conclusions are reliable.

Multilevel for Windows (MLWIN) was used for the MLAanalyses (version 1·0, Goldstein et al. 1998). Other analyses were carried out using SPSS for Windows (version $8 \cdot 0 \cdot 0$ ).

\section{RESULTS}

\section{Differences among nursing homes}

The percentage of residents feeling at home in each nursing home varied from 40 to $100 \%$ (Table 2). However, as some percentages were based on interviews with very few (four or five) residents, we also looked at differences between homes with at least 15 residents being interviewed. The range became smaller (59-96\%), but there was still a significant difference between nursing homes.

\section{[ TABLE 2 ]}

The percentage of respondents reporting disturbance caused by other residents varied (Table 2) but this variation was not statistically significant.

Intraclass correlation coefficients were computed to investigate whether residents in one nursing home had a greater degree in similarity of perceived privacy than residents of different nursing homes. Table 3 shows that $15 \%$ of the variance in resident-centredness was among nursing homes, whereas the remaining $85 \%$ was attributable to the characteristics of an individual resident. We can conclude 
that there are differences between nursing homes in resident-centredness. Table 3 shows that $9 \%$ of the total variance in perceived opportunities to create one's own environment (building) and $11 \%$ of the variance in flexibility of routines was because of differences between nursing homes.

\section{[ TABLE 3 ]}

\section{Determinants of feeling at home}

Bivariate relations between the resident's experience of feeling at home and characteristics of the residents are shown in Table 4. Statistically significant relationships with perceived privacy were found. Residents who did not feel at home more often said that there was insufficient opportunity to be on their own. They also judged the attitudes of the nurses as less resident-centred and more often said that they felt disturbed by other residents. We took a closer look at the items of the scales differentiating between residents feeling at home and those who did not. As far as the building was concerned, the most discriminating items were those governing the opportunity to talk with others in private (such as make private phone calls, receive visitors). With regard to resident-centredness, nine (out of 13) items discriminated. Showing interest in the resident, a quick response to a request for help, and a friendly attitude were important. Easy access to one's personal data also contributed to feeling at home.

\section{[ TABLE 4 ]}

Residents who did not feel at home had significantly different preferences. They more often stressed the importance of having the opportunity to be alone and create their own environment, and wanted more flexible routines/timetables. They also stressed the importance of the attitudes of nurses more often.

Residents with mental illness and residents staying in the nursing home longer generally felt more comfortable than those with physical illness and residents who had only recently been admitted.

As far as the location characteristics of the nursing homes were concerned, the only statistically significant relationship found was with the degree of urbanization. Nursing homes located in large or very large cities had a higher proportion of residents not feeling at home in the nursing home.

When all variables were entered in a logistic regression analysis, only few relations remained statistically significant (Table 5). Feeling at home was associated primarily with resident-centredness and disturbance caused by other residents. A weak relationship $(P<0 \cdot 10)$ was found with preferences towards flexible routines, residents' assessment of the building, and degree of urbanization. Residents taking the view that flexible routines are less important more often felt at home in a nursing home. Those who had more opportunities to be alone and create their own environment also felt more comfortable. Residents in urban areas tended to feel less at home than those in rural areas.

\section{[ TABLE 5 ]}

It can be concluded that most bivariate relations disappeared in a multivariate analysis. The disappearance of the bivariate relations was mainly due to differences between residents with physical illness and with mental illness. When the resident's illness was subject to control, the weakest bivariate relations disappeared. Residents with physical illness were in the nursing home for statistically significant shorter periods $(P<0.01)$ and had higher scores on the preferences scales $(P<0.001)$.

Residents with physical illness rated the characteristics of the building more positively $(P<0.05)$, had more flexible routines $(P<0.001)$ and judged the nurses as less resident-centred $(P<0.001)$.

\section{Multilevel analysis}

Multilevel analysis mainly confirmed these results. Residents not feeling at home tended to value flexible routines less $(t=1 \cdot 86, P<0 \cdot 10)$. However, most important determinants of feeling at home were resident-centredness $(t=4 \cdot 56, P<0.05)$ and disturbance caused by other residents $(t=3 \cdot 87, P<$ $0 \cdot 05)$. 
The MLA also indicated how much of the variability among nursing homes in the proportion of residents feeling at home was explained by the determinants. The parameter of variability of the null model (i.e. the model without predictor variables) was $0 \cdot 2278$. This means that the total variation in feeling at home is $0 \cdot 2278$. In five MLAs, we looked for changes in this parameter: (a) MLA with perceived privacy as predictor variables (resident level), (b) MLA with residents' preferences as predictor variables (resident level), (c) MLA with background characteristics of residents as predictor variables (resident level), (d) MLA with background characteristics of the nursing home (nursing home level) as predictor variables and (e) the full model including all predictor variables. The model showing the largest reduction in variability (parameter from $0 \cdot 2278$ to $0 \cdot 1071$ ) was the one with the perceived privacy variables (a). In the full model the parameter was 0 , indicating that all variability between nursing homes was explained by the predictor variables.

\section{Discussion}

Three of every four residents generally felt at home in their nursing home. Differences between nursing homes were found in the proportion of residents feeling at home. There were nursing homes with a considerable number of the respondents not feeling at home, and there were others with almost all respondents feeling at home. Feeling at home was related to resident-centredness and to disturbance caused by other residents. Whereas nursing homes did not differ in the degree to which residents disturb each another, there were differences in resident-centredness. Fifteen per cent of the chance that a resident feels well treated was determined by the nursing home. The influence of the home was fairly small but large enough to legitimate a general policy to improve the privacy within nursing homes. In addition, most variance was found at the individual level. This high level of heterogeneity among residents requires efforts from the staff to understand individual preferences and to respond adequately and appropriately.

Resident-centredness revealed itself particularly in the attitudes of nurses towards the residents. The conclusion that interpersonal relationships were most important is not new. In a study, by Grau et al. (1995) the quality of interpersonal relationships with nurses was found to be the basis for the majority of residents' best and worst experiences in the nursing home. How can interpersonal relationships between nurses and residents be improved? Firstly, working conditions are found to influence interpersonal relations. It is frequently stated that nurse burnout or distress is negatively associated with the quantity and quality of social interaction between themselves and residents (Jenkins \& Allen 1998). Jenkins and Allen (1998) found that those who felt involved in decisions relating to their work showed fewer negative interactions with residents. A shortage of nurses and a population with continually more complex health problems also puts a higher demand on nurses. Staff have less time to talk with residents. In The Netherlands, increased workload is a common complaint heard from nursing home staff and management (Meijer et al. 2000). Secondly, we expect that training programmes aimed at changing the attitudes of nurses would decrease the proportion of residents not feeling at home. Nurses should recognize the heterogeneity of residents in respect to their needs. Communication must be part of the programme because it is important when assessing the specific needs of older residents and providing nursing care that is tailored to the individual (Caris- Verhallen 1997).

Flexibility in routines is not associated with well-being. Routines can also be looked at in positive vein because they may give structure to the day (Mattiassion et al. 1997). A time schedule, for example meal routines, may function as a clock. Also, eating together is a social element in everyday life. From this viewpoint meal routines may promote wellbeing. However, other routines, such as lavatory routines (for example, three times a day), as well as waiting times (to get dressed sometime in the day) may diminish well-being.

The characteristics of the building were weakly related to feeling at home. In particular the opportunity to speak to someone in private (by telephone or face-to-face) is important. It is not a matter of creating single rooms (the number of beds in one room was not found to relate to feeling at home), but changes in the structure of the building might be necessary. These changes might also decrease the disturbance caused by other residents, which was found to be an important predictor of feeling at home.

Differences were found between residents with physical and mental illness. Residents with physical illness more often do not feel at home. In general, they want more privacy, resulting in higher 
preference-scores for the requirements of the building, flexibility of routines, and resident-centredness. The practical implication of the study is that it is important to take into account the main problem of the resident. However, the difference between these categories can also be the result of differences in interviewee. Almost all information about the residents with mental illness was gathered by proxyinterviews, whereas most residents with physical illness were interviewed themselves. Family members of residents with mental illness may underestimate their need for privacy.

Finally, a comment should be made concerning the methods used. The questions only had two response-alternatives ('yes' and 'no'). This may affect the validity of the answers. However, residents having difficulty in communicating (the majority of residents with physical illness had a cerebrovascular accident) were able to participate in the study and to express their opinion. Most residents did not experience difficulty in having only two alternative answers. Using a more complex questionnaire with more response-alternatives might further reduce the percentage of residents able to express their opinion.

\section{ACKNOWLEDGEMENT}

This research project is financed by the Ministry of Health, Welfare and Sports, The Netherlands.

\section{REFERENCES}

Bauman S.L. (1993) The meaning of being homeless. Scholary Inquiry of Nursing Practice: An International Journal 7, 59-73.

Bliesmer M.\&Earle P. (1993) Research considerations: nursing home quality perceptions. Journal of Gerontological Nursing 19, 27-34.

Brubaker B.H. (1996) Self-care in nursing home residents. Journal of Gerontological Nursing 22, 2230.

Caris-Verhallen W.M.C.M. (1997) The role of communication in nursing care for elderly people: a review if the literature. Journal of Advanced Nursing 25, 915-933.

De Veer A.J.E. \& Kerkstra A. (1998) Bewonerspanel verpleeghuizen (Measuring Opinions of Residents of Nursing Homes). NIVEL, Utrecht, The Netherlands.

Goldstein H., Rasbash J., Plewis I., Draper D., Browne W., Yang M., Woodhouse G. \& Healy M. (1998) A User's Guide to MLWIN. University of London, London.

Grau L., Chandler B. \& Saunders C. (1995) Nursing home residents' perceptions of the quality of their care. Journal of Psychosocial Nursing and Mental Health Services 33, 34-41.

Hammer R.M. (1999) The lived experience of being at home. A phenomenological investigation. Journal of Gerontological Nursing 25, 10-18.

Hox J.J. (1995) Applied Multilevel Analysis. TT-publikaties, Amsterdam.

Jenkins H. \&Allen C. (1998) The relationship between staff burnout/ distress and interactions with residents in two residential homes for older people. International Journal of Geriatric Psychiatry 13, 466-472.

Jirovec M.M. \& Maxwell B.A. (1993) Nursing home residents: functional ability and perceptions of choice. Journal of Gerontological Nursing 19, 10-14.

Kane R.A., Caplan A.L., Urv-Wong E.K., Freeman I.C., Aroskar M.A. \& Finch M. (1997) Everyday matters in the lives of nursing home residents: wish for and perception of choice and control. Journal of American Geriatric Society 45, 1086-1093.

Kruzich J.M., Clinton J.F. \& Kelber S.T. (1992) Personal and environmental influences on nursing home satisfaction. Gerontologist 32, 342-350.

Lavizzo-Mourey R.J., Zinn J. \& Taylor L. (1992) Ability of surrogates to represent satisfaction of nursing home residents with quality of care. Journal of American Geriatric Society 40, 39-47.

Like R. \& Zyzanski S.J. (1987) Patient satisfaction with clinical encounter: social psychological determinants. Social Science and Medicine 24, 351-357.

Linder-Pelz S. (1982) Toward a theory of patient satisfaction. Social Science and Medicine 16, $577-$ 582.

Mattiassion A.C. \& Andersson L. (1997) Quality of nursing home care assessed by competent nursing home patients. Journal of Advanced Nursing 26, 1117-1124.

Meijer A., Van Campen C. \& Kerkstra A. (2000) A comparative study of the financing, provision and quality of care in nursing homes. The approach of four European countries. Belgium, Denmark, Germany and the Netherlands. Journal of Advanced Nursing 32, 554-561.

Pearson A., Hocking S., Mott S. \& Riggs A. (1993) Quality of care in nursing homes: from the resident's perspective. Journal of Advanced Nursing 18, 20-24. 
Veer, A.J.E. de, Kerkstra, A.

Feeling at home in nursing homes.

Journal of Advanced Nursing: 35, 2001, nr. 3, p. 427-434

Post M. (1997) Living with spinal cord injury. A study of health status and life satisfaction of independently living people with a spinal cord injury. Thesis. Elinkwijk, Utrecht.

Ribbe M.W. (1993) Care for the elderly: the role of the nursing home in the Dutch health care system. International Psychogeriatrics 5, 213-222.

Spaan J.M. \& Bartels L.P. (1999) Verpleeghuiszorg in cijfers 1993-1997. NZi/NVVz, Utrecht.

Swan J.E., Sawyer J.C., van Matre J.G. \& McGee G.W. (1985) Deepening the understanding of hospital fulfilment and equity effects. Journal of Health Care Marketing 5, 7-18.

Van Thiel G. \& Van Delden J. (1997) Dealing with patient autonomy in Dutch nursing homes. Health Care in Later Life 2, 77-86.

VWS (1996a) Privacy in verpleeghuizen. Beleidsbrief aan de voorzitter van de Tweede Kamer (Privacy in nursing homes. Policy Document). SDU, Den Haag.

VWS (1996b) Landelijk sectoraal beleidstoetsingskader voor de sector verpleeghuizen (Building Guidelines for Nursing Homes. Policy document). VWS, Rijswijk.

Wade D.T. \& Hewer P.L. (1987) Functional abilities after stroke: measurement, natural history and prognosis. Journal of Neurological Psychiatry 50, 177-182.

\section{TABLES AND FIGURES}

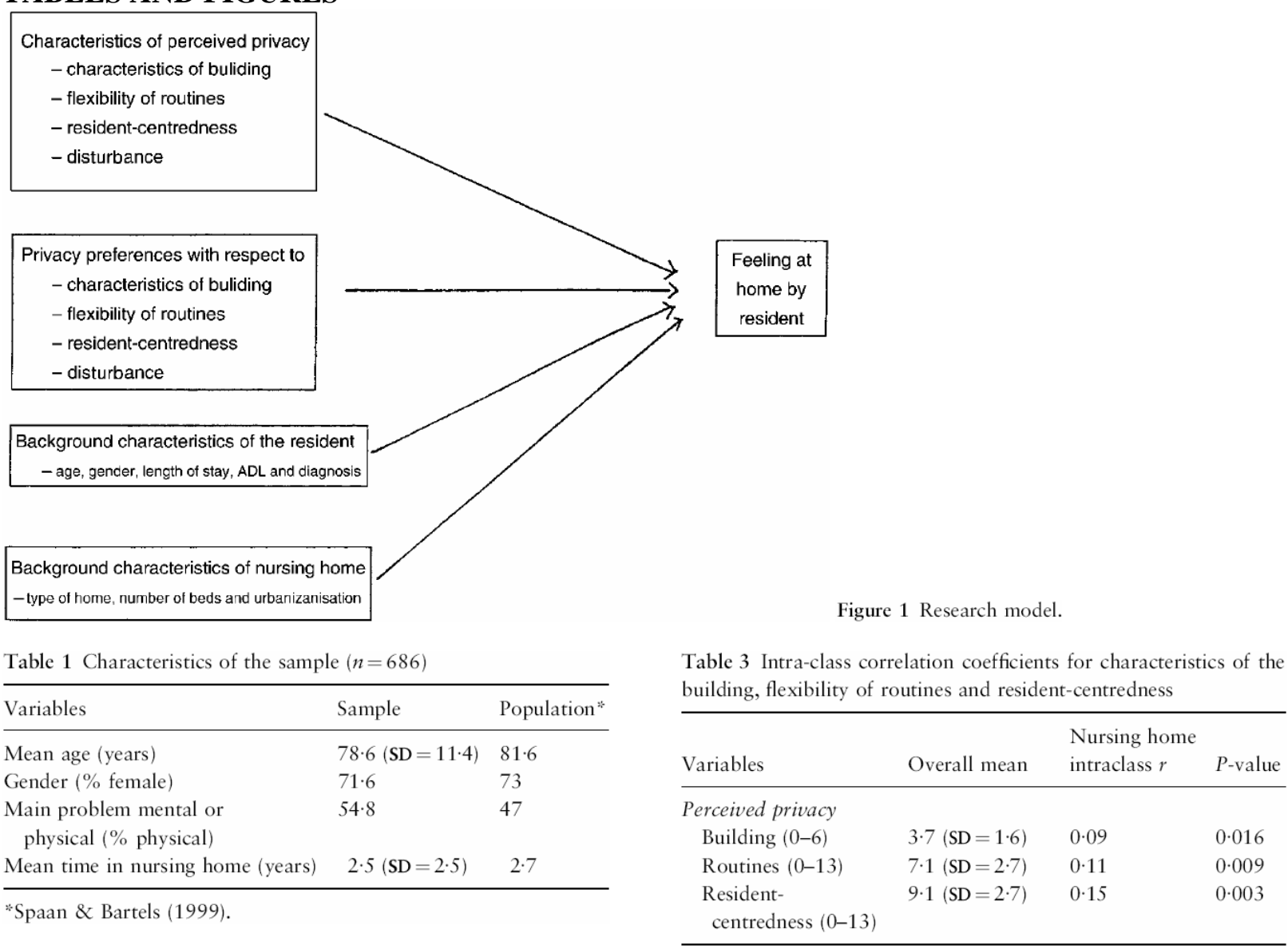

Table 2 Variability between nursing homes in percentage of residents feeling at home and percentage of residents experiencing disturbance caused by others $(n=686)$

\begin{tabular}{|c|c|c|c|c|c|c|}
\hline \multirow[b]{2}{*}{ Variables } & \multirow{2}{*}{$\begin{array}{l}\text { Overall } \\
\text { mean }\end{array}$} & \multicolumn{2}{|c|}{$\begin{array}{l}\text { All nursing homes }(\%) \\
(n=36)\end{array}$} & \multicolumn{2}{|c|}{$\begin{array}{l}\text { Nursing homes with } 15 \text { or more } \\
\text { respondents }(\%)(n=21)\end{array}$} & \multirow[b]{2}{*}{$P$-value } \\
\hline & & Minimum & Maximum & Minimum & Maximum & \\
\hline Feeling at home & $78 \cdot 3$ & $40 \cdot 0$ & 100 & $59 \cdot 4$ & $96 \cdot 3$ & $0.013^{*}$ \\
\hline Disturbance caused by others & $48 \cdot 8$ & 0 & $80 \cdot 0$ & $40 \cdot 7$ & $73 \cdot 1$ & $0 \cdot 689^{\dagger}$ \\
\hline
\end{tabular}

"Differences between nursing homes with 15 or more respondents are tested using chi-square analysis. $H_{\mathrm{o}}$ : Percentage of residents feeling at home is the same in all ( $n=21)$ nursing homes, $H_{\mathrm{a}}$ : there is a difference between nursing homes in percentage of residents feeling at home. $\uparrow$ Differences between nursing homes with 15 or more respondents are tested using chi-square analysis. $H_{\mathrm{o}}$ : Percentage of residents experiencing disturbance is the same in all $(n=21)$ nursing homes, $H_{a}$ : there is a difference between nursing homes in percentage of residents experiencing disturbance. 
Veer, A.J.E. de, Kerkstra, A.

Feeling at home in nursing homes.

Journal of Advanced Nursing: 35, 2001, nr. 3, p. 427-434

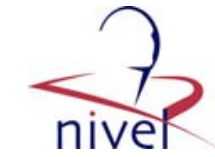

Table 4 Bivariate relations between determinants and feeling at home $(n=686)$

\begin{tabular}{|c|c|c|c|c|c|}
\hline \multirow[b]{2}{*}{ Variables } & \multirow{2}{*}{$\begin{array}{l}\text { Feeling at home } \\
(n=537)\end{array}$} & \multirow{2}{*}{$\begin{array}{l}\text { Not feeling at } \\
\text { home }(n=149)\end{array}$} & \multicolumn{2}{|c|}{$95 \%$ CI of the difference } & \multirow[b]{2}{*}{$P$-value } \\
\hline & & & Lower & Upper & \\
\hline \multicolumn{6}{|l|}{ Perceived privacy } \\
\hline Building (0-6) (mean) & $3 \cdot 80$ & $3 \cdot 32$ & $0 \cdot 20$ & $0 \cdot 77$ & $0 \cdot 001$ \\
\hline Routines (0-13) (mean) & $7 \cdot 12$ & 6.91 & $-0 \cdot 27$ & $0 \cdot 70$ & $0 \cdot 378$ \\
\hline Resident-centredness (0-13) (mean) & $9 \cdot 47$ & $7 \cdot 93$ & 1.00 & 2.08 & $0 \cdot 000$ \\
\hline Disturbance $(\%)$ & $47 \cdot 0$ & $66 \cdot 4$ & $-28 \cdot 6$ & $-10 \cdot 2$ & $0 \cdot 000$ \\
\hline \multicolumn{6}{|l|}{ Resident's preferences } \\
\hline Building (0-6) (mean) & 3.76 & $4 \cdot 12$ & $-0 \cdot 70$ & $-0 \cdot 02$ & $0 \cdot 035$ \\
\hline Routines (0-13) (mean) & $7 \cdot 57$ & $8 \cdot 66$ & $-1 \cdot 66$ & $-0 \cdot 51$ & $0 \cdot 000$ \\
\hline Resident-centredness (0-13) (mean) & $8 \cdot 82$ & $9 \cdot 44$ & $-1 \cdot 17$ & $-0 \cdot 07$ & $0 \cdot 026$ \\
\hline Disturbance $(\%)$ (mean) & $75 \cdot 9$ & $82 \cdot 6$ & $-14 \cdot 4$ & $1 \cdot 0$ & $0 \cdot 114$ \\
\hline \multicolumn{6}{|l|}{ Background variables of resident } \\
\hline Age (years) (mean) & $78 \cdot 68$ & $78 \cdot 24$ & $-2 \cdot 13$ & $3 \cdot 02$ & 0.735 \\
\hline Gender ( $\%$ female) & $73 \cdot 2$ & $65 \cdot 9$ & $-1 \cdot 2$ & $15 \cdot 8$ & $0 \cdot 118$ \\
\hline Barthel (mean) & $7 \cdot 29$ & $7 \cdot 40$ & $-0 \cdot 11$ & $0 \cdot 54$ & $0 \cdot 839$ \\
\hline Main problem (\% physical illness) & $52 \cdot 6$ & $62 \cdot 7$ & $-19 \cdot 4$ & $-0 \cdot 8$ & $0 \cdot 041$ \\
\hline Time in nursing home (years) (mean) & $2 \cdot 66$ & $2 \cdot 01$ & $0 \cdot 15$ & $1 \cdot 15$ & $0 \cdot 011$ \\
\hline Room (number of beds) (mean) & $2 \cdot 08$ & $2 \cdot 08$ & $-0 \cdot 14$ & $0 \cdot 15$ & $0 \cdot 930$ \\
\hline \multicolumn{6}{|l|}{ Background characteristics of nursing home } \\
\hline \multicolumn{6}{|l|}{ Type of home } \\
\hline Mental illness only (\%) & $11 \cdot 5$ & $10 \cdot 7$ & $-5 \cdot 0$ & $6 \cdot 4$ & $0 \cdot 932$ \\
\hline Combined $(\%)$ & $70 \cdot 9$ & $72 \cdot 5$ & $-9 \cdot 8$ & $6 \cdot 6$ & \\
\hline Number of beds (mean) & $179 \cdot 05$ & $185 \cdot 82$ & $-18 \cdot 3$ & $4 \cdot 63$ & $0 \cdot 243$ \\
\hline Urbanization (high refers to more urban) (mean) & $3 \cdot 34$ & $3 \cdot 71$ & $0 \cdot 10$ & $0 \cdot 48$ & $0 \cdot 000$ \\
\hline Variables & $\begin{array}{l}\text { B regression } \\
\text { coefficient }\end{array}$ & $P$-value & $\begin{array}{l}\text { a nursing } \\
\text { regressior }\end{array}$ & $\begin{array}{l}\text { inants of fe } \\
\text { using multi } \\
\text { sis }(n=686\end{array}$ & $\begin{array}{l}\text { at home in } \\
\text { gistic }\end{array}$ \\
\hline \multicolumn{6}{|l|}{ Perceived privacy } \\
\hline Building & $0 \cdot 14$ & $0 \cdot 084$ & & & \\
\hline Routines & $-0 \cdot 04$ & $0 \cdot 513$ & & & \\
\hline Resident-centredness & $0 \cdot 20$ & $0 \cdot 000$ & & & \\
\hline Disturbance & $-0 \cdot 49$ & $0 \cdot 000$ & & & \\
\hline \multicolumn{6}{|l|}{ Resident's preferences } \\
\hline Building & $0 \cdot 07$ & $0 \cdot 422$ & & & \\
\hline Routines & $-0 \cdot 10$ & $0 \cdot 066$ & & & \\
\hline Resident-centredness & $0 \cdot 00$ & $0 \cdot 991$ & & & \\
\hline Disturbance & $-0 \cdot 14$ & $0 \cdot 347$ & & & \\
\hline \multicolumn{6}{|l|}{ Background variables of resident } \\
\hline Age & $-0 \cdot 01$ & $0 \cdot 346$ & & & \\
\hline Gender & $-0 \cdot 15$ & $0 \cdot 253$ & & & \\
\hline Barthel & $0 \cdot 01$ & $0 \cdot 528$ & & & \\
\hline Main problem & $-0 \cdot 09$ & 0.589 & & & \\
\hline Time in nursing home & $0 \cdot 10$ & $0 \cdot 131$ & & & \\
\hline Room (number of beds) & $0 \cdot 11$ & $0 \cdot 468$ & & & \\
\hline \multicolumn{6}{|l|}{ Background characteristics of nursing home } \\
\hline \multicolumn{6}{|c|}{ Type of home } \\
\hline \multicolumn{6}{|l|}{ - Residents with physical illness only (reference group) } \\
\hline - Residents with mental illness only & $0 \cdot 16$ & $0 \cdot 566$ & & & \\
\hline - Both groups & $-0 \cdot 31$ & $0 \cdot 233$ & & & \\
\hline Number of beds & $0 \cdot 00$ & 0.992 & & & \\
\hline Urbanization & $0 \cdot 19$ & $0 \cdot 096$ & & & \\
\hline Constant & $0 \cdot 14$ & $0 \cdot 908$ & & & \\
\hline
\end{tabular}

